\title{
Pengembangan Desain Pembelajaran Seni Tari Di Sekolah Dasar Berbasis Localgenius Knowledge Berpendekatan Integrated Learning
}

\author{
Ni Luh Sustiawati, ${ }^{1}$ Ni Ketut Suryatini, ${ }^{2}$ Anak Agung Ayu Mayun Artati ${ }^{3}$ \\ 1. Program Studi Pendidikan Sendratasik, 2. Jurusan Seni Karawitan, 3. Jurusan Tari \\ Fakultas Seni Pertunjukan, Institut Seni Indonesia Denpasar, Jalan Nusa Indah, 80235, Indonesia \\ E-mail: sustiawatiniluh @gmail.com
}

Pencatuman seni dalam program-program pendidikan dapat difungsikan untuk membantu pendidikan, khususnya dalam usahanya untuk menumbuhkembangkan peserta didik agar menjadi utuh, dalam arti cerdas nalar serta rasa, sadar rasa kepribadian serta rasa sosial, dan cinta budaya bangsa sendiri maupun bangsa lain. Localgenius knowledge atau pengetahuan kearifan lokal Bali sebagai identitas/kepribadian budaya bangsa wajib dilestarikan dan ditransformasikan sejak pendidikan usia dini melalui pengalaman belajar seni untuk menjadikan siswa mampu mewarisi dan mempertahankan nilai-nilai luhur kearifan lokal budaya Bali sebagai kekayaan budaya bangsa Indonesia.

Tujuan penelitian ini teridentifikasinya potensi localgenius Bali sesuai dengan topik dan tema kurikulum sekolah dasar sebagai sumber pengembangan desain pembelajaran seni tari di sekolah dasar berpendekatan Integrated Learning. Untuk mencapai tujuan tersebut, digunakan pendekatan Research and Development (R\&D). Penelitian tahun pertama ini diawali dengan research melalui beberapa tahapan yaitu (1) analisis kebutuhan; (2) analisis kurikulum di sekolah dasar; (3) analisis potensi localgenius Bali; (4) analisis komparasi antara hasil analisi kebutuhan, kurikulum sekolah dasar dan potensi localgenius Bali. Teknik pengumpulan data digunakan studi pustaka, wawancara, observasi, dokumentasi dan diskusi terarah, serta analisis datanya digunakan analisis deskriptif.

Hasil penelitian menunjukkan, hasil analisis kebutuhan bahwa adanya fenomena rasa nasionalisme dan kecintaan terhadap tanah air semakin menipis, maka hasil analisis kurikulum dipilihlah tema 3 yaitu "Hidup Rukun" dan tema 5 yaitu "Bangga Sebagai Bangsa Indonesia" di kelas 5 sekolah dasar. Hasil analisis Localgenius Bali, dipilih seni tradisi Bali yang masih lestari dan sarat dengan nilai-nilai luhur religius, etika, estetika, bela negara dan kepahlawanan, yaitu (1) Gebug Seraye (mewakili Bali Timur/Kabupaten Karangasem); (2) Med-medan (mewakili Bali Selatan/Kota Denpasar); (3) Megoak-goakan (mewakili Bali Utara/Kabupaten Buleleng); dan (4) Makepung (mewakili Bali Barat/Kabupaten Jembrana).

Kata kunci: pembelajaran seni tari, localgenius knowledge,integrated learning

\section{Development Of Dance Learning Design In Elementary School With Local Genius Knowledge Basis And Integrated Learning Approach}

Specifying the arts within the educational programs may take a position to function as the supportive subject for the education itself, particularly in the effort to develop the holistic quality of the students in terms of not just in cognitive, but also regarding their sensitivities: the sense of personality and sociality, the sense of love to the national culture, the other culture as well. The local genius knowledge of Bali has been the identity/personality of the national culture. This must be preserved and transformed to the next generations since their preschool period through some art learning experiences. These experiences shall enable them to inherit and maintain the noble values of the Balinese culture as the national cultural assets of Indonesia. 
This research aims at identifying the Balinese local genius potentials in accordance with the elementary school curriculum theme which then to be chosen as the source of the learning design development of dancing in the elementary school applying integrated learning approach. To pursue this aim, the research and development $(R \& D)$ approach was applied. The first period of the research was initiated through several processes as (1) needs analysis, (2) elementary school curriculum analysis, (3) analysis of Balinese local genius potentials, and (4) comparative analysis between the results of the needs analysis, the elementary school curriculum analysis, and the analysis of Balinese local genius potentials. The data were collected through some techniques as literature study, interview, observation, documentation, and purposive discussion. Then, the data were analyzed descriptively.

The result of the research focuses on the needs analysis that shows a phenomenon of sense of nationalism degradation. Based on the curriculum analysis, therefore, the 3rd "Hidup Rukun (living in harmony)" and the 5th "Bangga sebagai Bangsa Indonesia (proud to be Indonesian)" theme were chosen for the 5th grade elementary school students. According to the result of the Balinese local genius analysis, it has been transformed to the students the existing Balinese traditional arts which is rich in noble religious, ethic, aesthetic, state defense, and heroism values as (1) Gebug Seraya (representing the East Bali/Karangasem Regency), (2) Med-medan (representing the South Bali/Denpasar City), (3) Magoak-goakan (representing the North Bali/Buleleng Regency), and (4) Makepung (representing the West Bali/Jembrana Regency).

Keywords : Learning the art of dance, local genius knowledge, integrated learning

Proses Review : 19 April - 4 Mei 2017, Dinyatakan Lolos : 8 Mei 2017

\section{PENDAHULUAN}

Meskipun upaya pembaharuan telah diupayakan oleh pemerintah dan berbagai standar sudah disusun untuk mewujudkan mutu pendidikan di tanah air, hingga saat ini proses pembelajaran belum dapat berlangsung secara efektif. Seperti halnya permasalahan di lapangan untuk pengem-bang kurikulum pendidikan seni di sekolah dasar, diantaranya merancang program pembelajaran yang dapat diimplementasikan oleh guru kelas kurang memperoleh pelatihan khusus, kurangnya pengetahuan terutama tentang konsep dan tujuan menari untuk pendidikan, baik dari pihak sekolah, orang tua murid, siswa bahkan guru sendiri dalam merancang program pembelajaran cendrung men-jadi kurang kreatif, pelajaran menari terkadang tidak sesuai dengan tingkat perkembangan siswa, bahkan siswa tidak mengetahui makna tari dan gerak. Padahal dalam gerak banyak mengandung arti dan makna dimana guru secara kreatif dapat menghubungkan dengan nilai-nilai kehidupan siswa secara luas.
Permasalahan tersebut di atas juga ditemukan di sekolah dasar di Bali, seperti pembelajaran menari, siswa diberikan tarian yang sudah jadi (tari bentuk) yang terkadang tidak sesuai dengan tingkat perkembangannya, bahkan siswa tidak mengetahui makna tari dan gerak. Oleh karena itu melalui penelitian ini dikembangkan desain pembelajaran seni tari sesuai dengan kebutuhan pembelajaran siswa sekolah dasar dengan pe-manfaatan pengetahuan keunggulan-keunggulan budaya daerah (localgenius knowledge) Bali yang merupakan bagian kehidupan budaya anak didik sehari-hari dan dikemas melalui pembela-jaran terpadu (integrated learning), sehingga memberi beragam pengalaman belajar bagi anak untuk tercapainya tujuan pembelajaran seni lebih bermakna.

Pengembangan adalah proses penerjemahan spesifikasi desain ke dalam bentuk fisik (Seels \& Richey, 1994). Kawasan pengembangan dalam pembelajaran menghasilkan suatu produk berupa materi, media, alat dan/strategi pembelajaran, digunakan mengatasi masalah praktis dalam dunia pendidikan, khususnya masalah pembelajaran di kelas atau 
laboratorium. Desain bermakna adanya keseluruhan, struktur, kerangka atau outline, dan urutan atau sistematika kegiatan (Gagnon dan Collay, 2001). Pembelajaran (instruksional) adalah suatu usaha yang disengaja, bertujuan, dan terkendali agar orang lain belajar atau terjadi perubahn yang relatif menetap pada diri orang lain (Miarso, 2004). Sedangkan desain pembelajaran secara sederhana adalah suatu rancangan yang sistematis dan sistemik untuk mencapai tujuan pembelajaran tertentu.

Seni Budaya dan Prakarya atau yang biasa disebut sebagai SBdP adalah salah satu mata pelajaran yang ada dalam Kurikulum 2013 dan berlaku untuk sekolah dasar. Pada pelajaran SBdP peserta didik mempelajari hal-hal mengenai budaya dan juga berkarya seni yang diajarkan secara kon-tekstual dan konkret, utuh, serta menyeluruh mencakup semua aspek (seni rupa, seni musik, seni tari dan prakarya) melalui pendekatan te-matik. Untuk itu para pendidik seni harus memiliki wawasan yang baik tentang eksistensi seni budaya yang hidup dalam konteks lingkung-an sehari-hari di mana ia tinggal, maupun penge-nalan budaya lokal, agar peserta didik mengenal, menyenangi dan akhirnya mempelajari. Dengan demikian pembelajaran seni budaya dan prakarya di sekolah dasar harus dapat memanfaatkan lingkungan sebagai kegiatan apresiasi dan kreasi seni.

Bidang seni tari merupakan salah satu media berkomunikasi (berekspresi seni) yang memiliki daya tarik bagi anak SD. Berkreasi seni tari dapat mengembangkan kompetensi dasar motorik halus yang sesuai dengan masa-masa perkembangan yang bersifat polos, unik, kreatif, spontanitas, dan dinamis. Pemberian pengalaman belajar pada masa peka ini merupakan saat yang paling baik, karena dapat mengembangkan kemampuan anak baik fisik dan psikis secara utuh dan bermakna. Pembelajaran seni tari di sekolah dasar kaitannya dengan Kurikulum 2013 (K-13) orientasi materi terkait pada karakteristik siswa, mengarah pada aspek budaya lokal dan nilai-nilai ke-Nusantara-annya. Pada intinya ada akar-akar budaya etnik bertolak pada spiritualitas, karena sumber seni tari berkembang di berbagai wilayah etnik bersumber dari tradisi ritual masyarakatnya.

Dasar budaya lokal dan nilai-nilai ke-Nusantaraannya yang telah ditumbuhkan dari jenjang usia sekolah (SD) diharapkan membentuk nilai-nilai pribadi yang meliputi (a) menunjukan pemahaman positif tentang diri dan percaya diri. Ini hasil dari pembentukan pribadi yang positif. Semua penampilan tari etnik di Indonesia menunjukan pola kepribadian yang positif, yaitu kegagahan, keperkasaan, kelembutan, atau kesetiaan; (b) menunjukan kemampuan untuk berinteraksi dengan orang lain dan alam sekitar. Ini hasil dari pem-bentukan nilai-nilai sosial untuk menyadari tentang kehidupan itu adalah proses. Jenis tari etnik daerah di Indonesia menunjukan sebuah proses untuk mencapai sebuah kebenaran, yaitu tentang kejahatan akan berakhir dengan kekala-han, kebaikan akan mencapai pada keluhuran; (c) menunjukan berpikir runtut. Ini menunjukan pada nilai tentang proses menuju hasil yang dicapai. Tari etnik di Indonesia mempunyai dasar konsep-tual. Ada nilai-nilai pikiran, logika, dan rasiona-litas; (d) berkomunikasi secara efektif, ini menun-jukan bahwa intelektualitas memilih dan memilah adalah potensi manusia yang mampu mencapai tingkat kualitas hidup. Tari etnik di Indonesia pada dasarnya mempunyai potensi sebagai media komunikasi, tidak hanya komunikai antar manusia, namun juga sebagai media komunikasi dengan roh dan alam semesta; (5) terbiasa hidup sehat, ini adalah nilai yang mengarah pada penghargaan tentang hidup, sehingga hidup itu adalah memiliki arti penting. Tari etnik di Indonesia menujukan dasar pembentukan dan pemeliharaan tubuh, sehingga mampu memper-tahankan kecantikan, keperkasaan, dan ketang-kasan; (e) menunjukan kematangan fisik. Ini adalah nilai yang menghargai tentang fungsi tubuh/badan sebagai media untuk mencapai tingkat keterampilan. Bahwa hidup ini akan dihadapakan pada sejumlah pekerjaan. Semua jenis tari etnik di Indonesia diperoleh dari hasil kedisiplinan dan kerja keras, karena di dalamnya memiliki konsep tentang nilai estetik yang tinggi.

\section{METODE PENELITIAN}

Penelitian ini menggunakan pendekatan research and development. Penelitian dirancang dalam tiga tahap dalam kurun waktu 3 tahun. Pada tahun pertama, penelitian ini bertujuan mengkaji dan mengakomodasi tema-tema pada kurikulum 2013 di sekolah dasar serta mengkaji localgenius knowledge Bali melalui literatur review dan survey di lapangan yang nantinya dijadikan sum-ber pengem 
bangan desain pembelajaran seni tari di sekolah dasar. Pada tahun kedua, penelitian ini bertujuan mengembangkan (membuat) desain pembelajaran seni tari di sekolah dasar berbasis local genius knowledge berpendekatan integrated learning. Pengembangan desain pembelajaran terkait dengan strategi pengorganisasian isi pelaja-ran dan strategi penyampaian isi pelajaran. Selan-jutnya pengujian desain pembelajaran, yaitu dila-kukan pengujian materi ajar melalui tiga tahap, yakni tahap pertama uji pakar (dosen) dan pengguna/user (guru); tahap kedua uji publik melalui lokakarya (focus group discussion) dan uji coba tahap ke tiga melalui penelitian tindakan kelas (PTK). Pada tahun ketiga, penelitian ini bertujuan mengetahui efektivitas dan kepraktisan desain pembelajaran seni tari. Sumber data dalam penelitian ini meliputi kalangan seniman, tokoh seni budaya, perumus kebijakan, kepala sekolah, guru, dan ahli pendidikan. Data dikumpulkan dengan teknik observasi, wawancara mendalam, studi kepustakaan, dokumentasi dan angket. Teknik yang digunakan untuk menganalisis data adalah analisis deskriptif. Analisis secara deskrip-tif dilakukan untuk mengkaji hasil-hasil yang sudah diperoleh pada uji coba tahap I, II, dan III. Selanjutnya, untuk mengetahui layak/tidaknya desain pembelajaran tari berbasis kearifan lokal yang dikembangkan menggunakan kriteria yang sudah ada.

\section{ANALISIS DAN INTERPRETASI DATA}

Berdasarkan Local genius knowledge Bali yang sudah disesuaikan dengan tema pada kurikulum 2013 di sekolah dasar, maka dipilihlah seni tradisi (1) Gebug Seraya merupakan seni tradisi Kabupaten Karangasem (mewakili Bali Timur); (2) Medmedan merupakan seni tradisi Kota Denpasar (mewakili Bali Selatan); (3) Megoak-goakan merupakan seni tradisi Kabupaten Buleleng (mewakili Bali Utara) dan (4) Makepung merupa-kan seni tradisi Kabupaten Jembrana (mewakili Bali Barat). Pemilihan seni tradisi ini disesuaikan dengan dua tema yakni tema "Hidup Rukun" dan tema "Bangga Sebagai Bangsa Indonesia" di kelas 5 sekolah dasar. 3.1 Seni Tradisi Gebug Seraya

Gebug Seraya diperkirakan lahir pada saat terjadi kontak atau peperangan antara kerajan Karangasem dengan Lombok, yaitu sejak jatuhnya kerajaan Pejanggik pada tahun 1692 dengan mulainya Karangasem menanamkan kekuasaan-nya di pulau
Lombok, sehingga pada tahun 1744 sudah berdiri kerajaan-kerajaan kecil di Lombok Barat yang semuanya diperintah oleh satu keluar-ga berasal dari Karangasem Bali. Peperangan yang terjadi antara kerajaan Karangasem dengan Lombok melibatkan orang-orang Seraya sebanyak 40 orang (sorohan petang dasa) sebagai pasukan atau prajurit pilihan Raja Karangasem (I Gusti Ketut Karangasem) bersenjatakan tombak dan perisai yang posisinya ada di barisan paling depan (Agung, 1981:13-20).

Menurut pemaparan Bapak Nyoman Matal (Bendesa Adat desa Seraya Karangasem), Gebug Seraya berasal dari dua kata yaitu Gebug dan Seraya. Gebug artinya memukul, megebug artinya saling memukul, magegebug berarti penyerangan atau berperang. Sedangkan kata Seraye bisa dimaknai sebagai nama desa Seraye, juga bisa dimaknai sebagai kanti atau teman (dalam bahasa Pedalang-an disebut kunti seraye) yang siap membantu dalam hal ini membantu Raja dalam bidang keprajuritan (militer), baik untuk perang antar kerajaan di Bali maupun menghadapi kerajaan di luar Bali. Fungsi Gebug Seraya adalah: (1) sebagai sebuah permainan perang, terkait dengan peperangan pada masa-masa kerajaan Karanga-sem berfungsi melatih ketangkasan, kelihaian memainkan senjata (penyalin) dan tameng (ende) yang diimbangi dengan keberanian melawan musuh. Sesungguhnya yang terpenting dalam hal ini adalah makna yang terkandung di dalamnya, yaitu melatih kepintaran, melatih ketangkasan, melatih kekuatan, melatih kedisiplinan serta mela-tih kejujuran sebagai seorang abdi raja; (2) sebagai sebuah ritual menurunkan atau proses mengundang hujan apabila musim kemarau yang berkepanjangan melanda desa Seraya dengan mengadakan sebuah permainan; (3) sebagai sebuah hiburan rakyat oleh masyarakat Seraya Karangasem (wawancara 15 Juli 2016, di Seraya Barat).

Hari baik menurut tradisi masyarakat Seraya untuk menyelenggarakan Gebug Seraya sebagai ritual mendatangkan hujan dilaksanakan sesudah upacara usaba desa atau ngusaba di Pura Puseh yaitu Purnamaning Kapat setiap bulan keempat menurut perhitungan bulan atau kalender Bali bertempat di halaman (natah) Pura Bale Agung Desa Seraya yang konon merupakan tempat ber-kumpulnya prajurit-prajurit Seraya sebelum berangkat ke 
medan pertempuran, disini mereka mengadakan latihan memainkan tombak dan tameng. Satupersatu prajurit (sorohan petang dasa) kemudian masuk ke dalam (jeroan) Pura Puseh yang merupakan stana dari Dewa Wisnu untuk melempar tombak ke sebuah batu besar. Apabila tombak yang dilempar ke batu tersebut mengeluarkan api, berarti orang tersebut diperbo-lehkan ikut ke medan pertempuran, namun jika sebaliknya tombak yang dilempar patah, maka orang tersebut belum diperbolehkan untuk ikut. Maka dari itu Pura Bale Agung menjadi satu-satunya tempat yang dipercaya oleh para tokoh agama, adat serta seluruh masyarakat Seraya sebagai tempat dilangsungkannya ritual Gebug Seraya. Menurut Bapak Nyoman Matal jika dihubungkan dengan pura kahyangan desa, ada salah satu pura dengan sebutan Pura Bale Sang Hyang di desa Seraya. Bale ada yang memberikan arti rumah manusia, menurut saya makna bale dapat dilihat dari perubahan pengejaan yang pada akhirnya kata bale menjadi bala (prajurit). Berdasarkan kepercayaan dan keyakinan masyarakat desa Seraya, sampai saat ini bahwa Pura Bale Sang Hyang merupakan tempat para prajurit berlatih sebelum berperang dan di pura ini ada Arca Lingga Dewa Indra yang merupakan dewa perang sehingga atas restu Dewa Indra pasukan-nya menjadi kuat (wawancara 15 Juli 2016, di Seraya Barat).

Kewajiban terakhir yang harus ditaati oleh seluruh pemain pada saat magebug adalah mematuhi peraturan permainan. Aturan-aturan main tersebut berupa (1) Tidak boleh memukul di bawah pinggang; (2) Tidak boleh memukul lawan yang belum siap misalnya saat lawan sedang mencoba ende dan belum mengangkat ende untuk mulai berhadapan; (3) Tidak boleh memukul dengan membalikkan penyalin atau mempergunakan bongkol (pangkal) penyalin; (4) Tidak boleh memukul ketika lawan meminta berhenti sejenak (cub), misalnya karena ada sesuatu yang terlepas seperti udeng, saput maupun penyalin atau ende; (5) Tidak boleh melewati batas yang sudah ditentukan; (6) Tidak boleh maruket, hal ini biasanya terjadi ketika sudah terjadi kesengitan antara kedua pemain dan biasanya langsung di-lerai oleh pakembar atau saya (wasit) (wawancara dengan Bapak Komang Nisma, 17 Juli 2016).

\subsection{Seni Tradisi $M e d-m e d a n$}

Tradisi yang disebut Med-medan ini tampak sederhana, namun memiliki makna yang luas yakni makna religi, solidaritas dan budaya. Med-medan adalah suatu mitologi yang diterima sebagai warisan masyarakat Banjar Kaja Sesetan secara turuntemurun dari generasi tua sampai generasi saat ini. Menurut Tim Penyusun Kamus Bali Indonesia (dalam Munggah, 2008), kata dasar maomedomedan adalah omed. Kata omed diulang menjadi omed-omed mendapat konfiks ma-an, sehingga kata itu menjadi maomed-omedan (sekarang sering dinamakan Med-medan) yang artinya bertarik-tarikan (dalam kegiatan ini tanpa alat apapun alias tangan kosong).

Berdasarkan hasil wawancara dengan I Gusti Ngutah Oka Putra salah seorang keturunan Jero Banjar Kaja atau Puri Oka Banjar Kaja Kelurahan Sesetan menjelaskan awal pelaksanaan sebelum tahun 1980 tradisi Med-medan sebagai berikut, bahwa leluhurnya yang bernama Anak Agung Made Raka yang dijulukinya Ida Bhatara Kompiang oleh sentananya menjadi peтисиk atau mengatur pemerintahan di Desa Sesetan pada saat Hari Nyepi Ida Bhatara Kompiang menderita sakit keras, walau sudah diobati ke berbagai dukun, tetapi tidak sembuh, beliau sulit berdiri apalagi berjalan. Kepada warga di Banjar Kaja Se-setan beliau berpesan agar mereka tidak men-jenguk beliau dan jangan mengadakan keramaian atau ribut-ribut di depan Puri. Ketika Hari Nyepi tiba, warga di Banjar Kaja Sesetan sedih dan ke-cewa, karena adanya larangan seperti di atas. Di tengah kesedihan dan kekecewaan yang dirasakan masyarakat pada saat itu, ada beberapa di antara-nya yang mencoba melanggar larangan tokoh Puri dengan memberanikan diri tetap melaksanakan tradisi Med-medan yang telah diwarisinya sejak nenek moyangnya. Akhirnya Med-medan pun ramai seperti sedia kala. Ida Bhatara Kompiang sedang sakit keras di tempat tidurnya menjadi marah dan seketika itu juga memerintahkan ke-luarganya untuk menghantarkan beliau ke depan Puri, maksudnya tokoh Puri akan memarahi para abdinya, menghentikan keributan yang terjadi di depan puri dan akan mengusirnya, supaya suasana menjadi tenang. Pada saat beliau diantar ke luar Puri, sakitnya dirasakan berkurang dan sampai di tempat rakyat berkumpul sakitnya sama sekali tidak terasa dan merasa sehat seperti sedia kala. Seketika itu pula tokoh Puri mengurung 
kan niat beliau melarang keramaian, malahan berkehandak sebaliknya. Beliau kemudian menyarakan kepada khalayak, agar keramaian Medmedan diteruskan sesuai dengan tradisi yang ada dan Beliau merasa-kan ada sesuatu keajaiban yaitu yang pada awal-nya beliau sakit seketika menjadi sehat (wawan-cara, 5 Juli 2016).

Setiap tahun Med-medan dilaksanakan untuk menyongsong Tahun Baru Saka dikaitkan dengan ajaran agama, terutama rangkaian urutan melis, tawur, nyepi dan ngembak geni. yang merupakan ajang masimakrama. Upacara tradisi Med-medan ini diadakan pada hari ngembak geni dimulai tepat pukul 15.00 Wita, semua peserta dan Prajuru Banjar telah siap di tempat yang ditentukan (di Aula Bale Banjar) dengan urutan kegiatan, (1) upacara pembukaan singkat oleh Prajuru Banjar; (2) persembahyangan bersama; (3) dharma santi atau masimakrama dan tari-tarian Bali (tari lepas); (4) Med-medan di depan Bale Banjar; (5) makan bersama; dan (6) penutup.

Seni tradisi Med-medan memiliki kandungan nilai budaya yang mendalam, diantaranya: (1) Nilai Religi, yakni upacara ritual penghormatan (bakti) terhadap Leluhur dan Ida Hyang Widhi Wasa/ Tuhan Yang Maha Esa. Secara psikologis para peserta upacara percaya diri, merasa aman, dan optimis akan keselamatan dan kesejahteraan yang akan diterimanya, karena itu pelaksanaan upacara dilaksanakan secara rutin dengan rasa ketulusikhlasan. Dengan demikian, dapat dikatakan bahwa upacara tradisi Med-medan sebagai wadah kearifan lokal merupakan sarana masyarakat warga Banjar Kaja Kelurahan Sesetan sebagai salah satu bentuk perlindungan manusia untuk menghadapi hal-hal yang tidak diinginkan; (2) Nilai Kesetiakawanan (Menyama Braya), artinya tradisi Med-medan berfungsi sosial yaitu untuk memupuk rasa kesetiakawanan atau menyama braya di antara masyarakat warga Banjar Kaja Kelurahan Sesetan. Konsep saling asuh, saling asah dan saling asih, artinya; selalu mengutama-kan hidup yang selaras, serasi, harmonis dan berkeseimbangan dalam hubungannya dengan orang lain terbangun dalam pelaksanaan tradisi Med-medan dan menjiwai aktivitas sosial mereka dalam kehidupan sehari-hari di Banjar Kaja Kelurahan Sesetan; (3) Nilai Keharmonisan, tradisi Med-medan sebagai wadah kebersamaan dan sebagai wadah resolusi konflik, artinya guna menjaga keseimbangan dan keutuhan masyarakat di wilayah Banjar Kaja Kelurahan Sesetan memerlukan adanya pengendalian sosial yang dianggap dapat berperan positif dalam mengu-rangi ataupun menyelesaikan terjadinya konflik.; (4) Nilai Solidaritas, tradisi Med-medan sebagai wadah kearifan lokal ikut memupuk dan meles-tarikan solidaritas dan persatuan masyarakat warga Banjar Kaja Kelurahan Sesetan. Konsep saling asih, saling asah, saling asuh mengajarkan untuk memahami dan menghayati serta melaksanakan prinsip berperilaku untuk mencintai, mengajari, dan mengasuh atau mengawasi saudara dan tetangga dekat. Konsep ini juga berarti saling memberi dan saling meminta, baik dalam keadaan suka maupun duka (bergotong royong dalam hidup bermasyarakat); (5) Nilai Hiburan, tradisi Medmedan biasanya berlangsung semarak, keme-riahan itu diperlihatkan pemain Med-medan dan para penonton karena mampu memberi kesenang-an dan hiburan, dapat bertemu dengan kerabat lamanya, juga dapat berkenalan dengan kaum remaja putra/putri di tempat pertunjukan; (6) Nilai Ekonomi, secara sosio-ekonomis upacara pelaksanaan tradisi Med-medan merupakan salah satu institusi nonformal yang dapat menggerakkan masyarakat di Banjar Kaja Kelurahan Sesetan dalam rangka memenuhi kebutuhan hidup mereka. Para tamu yangdatang merupakan poten-si ekonomi yang dapat diperoleh masyarakat setempat sebagai hasil dari penyelenggaraan upa-cara pelaksanaan tradisi Med-medan. Tamu-tamu tersebut baik tamu asing maupun domestik tentu membelanjakan uangnya di Banjar Kaja Kelurah-an Sesetan, seperti membeli makanan, minuman, kipas asli cendana atau eben, dan barang-barang yang beraneka macam yang terpajang di toko-toko di pinggir jalan di sekitar lokasi itu.

\subsection{Seni Tradisi Magoak-goakan}

Magoak-goakan telah menjadi tradisi rakyat atau penduduk desa pakraman Panji Buleleng, biasa-nya dilaksanakan pada hari Ngembak Geni (sehari setelah hari raya Nyepi) di lapangan desa pakraman Panji. Nama Magoak-goakan diambil dari nama Burung Gagak (Goak yang gagah) yang terinspirasi ketika melihat burung ini tengah mengincar mangsanya. Magoak-goakan ini diper-kirakan sudah ada pada masa pemerintahan Ki Gusti Ngurah Panji Sakti di Buleleng (hasil wawancara dengan I Gusti Nyoman Tiga, 7 Juli 2016). 
Diceritakan pada suatu hari Ki Gusti Ngurah Panji Sakti sedang termenung memikirkan cara yang tepat untuk mengalahkan kerajaan Blambangan di Jawa Timur. Tiba-tiba beliau ter-sentak, karena di halaman istana para pemuda sedang bermain Magoak-goakan. Awalnya Ki Gusti Ngurah Panji Sakti hanya menyaksikan rakyatnya bermain Magoak-goakan, selanjutnya beliau mendapat satu gagasan bahwa permainan Magoak-goakan ini dapat dimanfaatkan untuk mencapai keinginannya menaklukkan kerajaan Blambangan. Beliau pun mengajak Truna Goak (rakyatnya) untuk bermain goak-goakan dan masing-masing gagak yang menang boleh minta sesuatu kepada raja sebagai hadiah. Hal tersebut menjadikan banyak prajuritnya ikut serta bermain Magoak-goakan. Kesempatan pertama raja me-nunjuk prajuritnya untuk menjadi goak (orang yang ada paling depan barisan) dan berusaha menangkap peserta yang paling belakang (ekor barisan, yang disebut kacang). Setelah semua pemain mendapat giliran jadi goak dan kacang, tibalah giliran raja untuk menjadi goak. Saat raja bermain, posisi raja dalam permainan itu mempunyai derajat yang sama dengan rakyatnya. Sang raja berusaha sekuat tenaga dapat menangkap ekor (pemain yang terakhir). Setelah ekor berhasil ditangkap oleh raja, maka raja berhak meminta hadiah dari rakyatnya. Adapun permintaan yang diminta oleh raja saat itu adalah kesediaan rakyat untuk bersedia bersama-sama menggempur kerajaan Blambangan di Jawa Timur. Rakyat bersorak untuk mendukung keinginan rajanya, dan per-mintaan raja tersebut mampu membangun prajurit yang tangguh, sebagai pertahanan kerajaan yang akan dilatih untuk melawan kerajaan Blambang-an. Tujuan sebenarnya adalah membangun dan mengobarkan semangat teruna goak melawan musuhnya yaitu kerajaan Blambangan di Jawa Timur (Simpen, 2002:34).

Magoak-goakan ini bertemakan kepahlawanan yang awalnya dimainkan oleh pemain putra yang diatur dengan pola lantai membentuk garis lurus berjejer, namun perkembangan selanjutnya seba-gai sebuah pertunjukan Magoak-goakan juga dimainkan oleh pemain putri. Adapun nilai-nilai yang dapat ditemukan dalam tradisi Magoakgoakan adalah: (1) Nilai Religi, tradisi Magoakgoakan ini menjadi tolak ukur masyarakat desa Panji untuk penghormatan terhadap Raja Ki Gusti Ngurah Panji Sakti dengan pasukannya yang bernama Truna Goak. Tradisi Magoak-goakan dapat dikaitkan dengan ajaran agama Hindu yaitu konsep Tri Hita Karana artinya tiga hubungan yang harmonis yang menyebabkan kebahagiaan bagi umat manusia. Tiga hubungan yang harmo-nis antar manusia dengan penciptanya (prahyang-an), manusia dengan alam (palemahan), dan manusia dengan sesamanya (pawongan). Dalam pelaksanaan Magoak-goakan melalui mendekat-kan diri dengan Dewa-Dewi dan para leluhur, diawali dengan persembahyangan di pura Paje-nengan Panji untuk memohon keselamatan agar manusia dapat menjalin rasa persaudaraan dan selalu menjaga lingkungannya; (2) Nilai Etika, tradisi Magoak-goakan mengandung nilai (a) kebenaran dan kejujuran. Unsur kebenaran dan kejujuran dalam Magoakgoakan dapat dilihat dari tokoh Ki Gusti Ngurah Panji Sakti saat rakyatnya bermain Magoakgoakan. Beliau ber-janji akan memberikan hadiah apapun yang diminta, jika prajurit goak tersebut berhasil menangkap ekor (prajurit yang berada paling belakang). Kejujuran dan kebenaran dari sikap Ki Gusti Ngurah Panji Sakti tersebut dapat mencer-minkan tindakan yang baik menjadikan dirinya sebagai orang yang selalu dapat dipercaya dalam perkataan, tindakan, dan pekerjaan, baik terhadap diri sendiri maupun pihak lain. Sikap kejujuran dan kebenaran tersebut sangat penting dan harus diterapkan pada lingkungan sekitar; (b) tanpa kekerasan, dalam Magoak-goakan dapat dilihat dari para pemain yang berlari-lari dan terjatuh berulang kali tanpa ada yang merasa dirugikan, para pemain juga menjaga barisan dengan meme-gang erat teman yang ada di depannya dan saling menjaga satu sama lain agar tidak terlepas dalam Magoakgoakan, hal ini menunjukkan sikap saling peduli; (c) kebajikan atau kemurahan hati, dalam Magoakgoakan dapat terlihat pada saat Ki Gusti Ngurah Panji Sakti melihat rakyatnya ber-main Magoakgoakan, dengan tidak adanya rasa malu beliau ikut langsung dalam permainan ter-sebut. Masyarakatpun terkejut karena biasanya permainan ini dilakukan oleh masyarakat biasa, namun seorang raja pun ingin ikut bermain. Beliau merupakan raja yang bisa berbaur dan santun dengan masyarakat. Sikap kemurahan hati dari Ki Gusti Ngurah Panji Sakti termasuk pendi-dikan budi pekerti (dharmadana) yang patut ditiru oleh setiap orang; (d) ketekunan dan kerja keras, dalam Magoak-goakan dapat dilihat dari pemain goak berlari-lari dan mengincar ekor (penari paling belakang). 
Goak disini dengan usaha dan ketekunannya mengincar ekor tersebut hingga tertangkap, dan sangat teliti dalam melihat gerak-gerik ekor yang selalu menghindar dari kejaran-nya, namun goak tetap bangkit dan semangat mengejar ekor tersebut hingga pada akhirnya dapat tertangkap. Pemain yang lain juga kerja keras menghalangi goak yang ingin mengincar ekor. Nilai ketekunan dan kerja keras yang terkan-dung dalam Magoak-goakan ini dapat diterapkan kepada masyarakat untuk selalu berusaha dengan kerja keras dan tekun agar mendapatkan hasil yang ingin dicapai; (e) keluhuran budi, dalam Magoak-goakan dapat dilihat dari sikap kesetia-kawanan sosial, solidaritas para pemain dengan gerakan-gerakan lincah yang kadang kala berlari, menari, jongkok, merayap berputar-putar, ber-balik, atau melompat ke sana ke mari untuk menjaga dan mempertahankan barisan agar terhindar dari incaran pemain goak, walaupun pada akhirnya ekor tersebut juga tertangkap. Kearifan lokal Magoak-goakan ini dapat mem-beri nilainilai penguatandan memperteguh peri-laku kesetiakawanan sosial yang sekarang ini semakin luntur, perlu dibangkitkan kembali sebagai pondasi memperkokoh kebhinekaan dan memperkuat restorasi sosial; (f) kepahlawanan. Pahlawan lekat sekali dengan tentara perang yang berjuang membela negara, mempertahankan ke-merdekaan, menjaga keamanan, rela berkorban, cinta tanah air, senasib sepenanggungan memiliki nilai filsafat yang luar biasa yang membuat tidak egois, tidak sombong dan selalu mengedepankan kepentingan umum di atas kepentingan pribadi dan golongan. Bangsa yang besar adalah bangsa yang mau dan mampu menghargai sejarah per-juangan para pendahulunya, oleh karena itu peng-galian dan pelestarian seni tradisi yang sarat deng-an nilai-nilai kepahlawanan terus dilakukan dan disebarluaskan serta diaktualisasikan oleh seluruh komponen bangsa; (2) Nilai Estetika, Magoak-goakan sebagai seni tradisi mengandung nilai keindahan yaitu dapat membangkitkan semangat dan rasa gembira bagi pemain dan para penonton-nya. Aksi kejar-kejaran yang dilakukan goak ingin menangkap ekor dan ekor dapat tertangkap oleh goak membuat penonton bersorak ria dan merasa terhibur.

\subsection{Seni Tradisi Makepung}

Makepung adalah seni tradisi yang berangkat dari keinginan untuk mengangkat kehidupan agraris dan kebudayaan tradisi masyarakat Kabupaten
Jembrana yaitu kabupaten yang terletak di Bali Barat. Sejak bulan Desember tahun 2013 Makepung telah ditetapkan sebagai warisan budaya tak benda (WBTB) Indonesia. Tradisi ini awalnya muncul dari kegiatan membajak sawah (proses melumatkan tanah menjadi lumpur) yang dilakukan secara gotong royong oleh para petani selama musim tanam di sawah. Dalam kegiatan mem-bajak tersebut digunakan dua ekor kerbau yang menarik bajak lampit slau (bajak kayu tradisional) yang ditunggangi oleh seorang joki/sais. Dalam kegiatan gotong royong membajak sawah tersebut terdapat banyak bajak lampit yang masing-masing ditunggangi oleh seorang joki/sais, mulai-lah timbul rasa untuk saling mengadu kekuatan kerbau mereka masing-masing. Hal itulah yang menjadi cikal bakal perlombaan yang dinamakan Makepung dalam bahasa Indonesia berarti ber-kejar-kejaran antara dua pasang kerbau atau lebih guna untuk menjadi pemenang.

Tradisi Makepung di sawah ini berkembang seki-tar tahun 1930 dan sais/jokinya berpakaian seperti prajurit Kerajaan di Bali jaman dulu yaitu meme-kai destar, selendang, selempod, celana panjang tanpa alas kaki dan di pinggang terselip sebilah pedang yang memakai sarung poleng (warna hitam putih). Oleh karena pakaian para sais/joki selalu kotor dilumuri lumpur setelah Makepung di sawah, maka mulai tahun 1960 tradisi Makepung diadakan di jalan tanah dekat sawah. Organisasi Makepung sekarang ini terdiri dari dua kelompok, yakni kelompok yang berada di sebelah timur sungai Ijo Gading (blok timur), diberi Nama "Regu Ijo Gading Timur" dengan lambang Ben-dera warna merah dan kelompok yang berada di sebelah barat Sungai Ijogading (blok barat), diberi Nama "Regu Ijo Gading Barat" dengan lambang Bendera Warna Hijau. Ijo Gading adalah nama sebuah sungai yang membelah jantung Kota Negara, ibu kota kabupaten Jembrana, menjadi dua bagian yaitu belahan kota sebelah barat sungai Ijo Gading dan belahan sebelah timur sungai Ijo Gading (wawancara dengan I Ketut Suwentra, 9 Juli 2016).

Sarana yang dipakai bukan lagi bajak lampit melainkan cikar/gerobak dengan ukuran yang lebih kecil yang dihiasi dengan ukiran di tambah aksesoris lain dan tongkat rotan yang berisi paku (alat pemukul kerbau). Cikar ini nantinya sebagai tempat si tukang lempang (joki) dalam mengen-dalikan 
kerbau. Tongkat rotan yang berisi paku digunakan untuk memukul kerbau agar ia terpacu lebih cepat dalam berlari, dan luka yang mem-bekas pada kulit kerbau dapat disembuhkan dengan obat tradisional, salah satunya memakai getah dari pohon pisang (diambil dari kerikan batang pohon pisang muda yang masih segar). Para sais/joki berbusana tradisional yaitu mema-kai destar batik, baju tangan panjang memakai selempod, memakai celana panjang dan memakai sepatu tetapi tidak menyelipkan pedang pada pinggang. Kerbau yang digunakan dalam perlom-baan makepung adalah kerbau jantan yang khusus dipersiapkan untuk Makepung. Kerbau jantan hitam disebut dengan kebo, sedangkan kerbau jantan putih (bule) disebut dengan misa. Kerbau-kerbau ini tidak hanya berasal dari Bali saja, tetapi dari luar Bali juga. Seperti dari Jawa dan Sula-wesi. Kerbau yang khusus untuk Makepung ini sudah dilatih sejak umur 2 tahun (wawancara dengan I Ketut Gama, 13 Juli 2016).

Sebagai upaya pelestarian, pengembangan dan penyebarluasan kepada generasi penerus, maka tradisi Makepung dilaksanakan setiap tahun, yaitu pada saat para petani selesai panen di sawah sekitar bulan Juli sampai Oktober, baik itu berupa latihan, pertandingan persahabatan, perebutan piala Bupati (Bupati cup) maupun perebutan piala Gubernur (Gubernur cup). Dalam tradisi Make-pung ini bukan hanya untuk mengejar materi semata melainkan untuk melestarikan suatu wari-san budaya lokal yang mempunyai nilai-nilai luhur dari para pendahulu kita (wawancara deng-an I Ketut Suwentra, 9 Juli 2016). Nilai-nilai luhur yang terkandung dalam tradisi Makepung adalah (1) dapat menciptakan rasa kekeluargaan, mempererat hubungan antar masyarakat, dan memupuk rasa kesetiakawanan di antara masya-rakat, sehingga dapat berperan positif dalam mengurangi ataupun menyelesaikan terjadinya konflik; (2) aspek religius yaitu rasa terima kasih dan wujud syukur terhadap karunia yang Tuhan Yang Maha Esa yang memberikan jiwa pada ciptaannya dan yang mengatur gerak atau pere-daran alam semesta ini; (3) memiliki nilai sema-ngat yang tinggi untuk mencapai tujuan; (4) mem-pertahankan konsep tradisi mengenang kehidupan masyarakat agragris terdahulu, yang mana saat ini sudah beralih dengan menggunakan teknologi mesin yaitu traktor, yang pada awalnya meng-gunakan kerbau untuk membajak sawah.
Berdasarkan analisis data yang telah diuraikan di atas, penelitian ini memberikan makna bahwa seni tradisi menjadi penting dan relevan dalam pengembangan nilai-nilai kebangsaan termasuk dalam pengembangan spirit bela negara sebagai salah satu komponen pertahanan nasional. Pema-haman mengenai seni tradisi yang berkelanjutan dalam perubahan (continuity in change) semesti-nya disandarkan pada nilai-nilai keTuhanan, kemanusiaan, dan lingkungan alam pada setiap zamannya, maka seni tradisi ini tetap relevan untuk membangun dan mengembangkan sistem nilai pada zaman kini serta seni tradisi Indonesia dapat menjadi komponen yang relevan dan signifikan dalam upaya membangun semangat bela negara.

\section{SIMPULAN}

Seni Budaya dan Prakarya atau yang biasa disebut sebagai SBdP adalah salah satu mata pelajaran yang ada dalam Kurikulum 2013 dan berlaku untuk sekolah dasar. Pada pelajaran SBdP peserta didik mempelajari hal-hal mengenai budaya dan juga berkarya seni yang diajarkan secara kontek-stual dan konkret, utuh, serta menyeluruh men-cakup semua aspek (seni rupa, seni musik, seni tari dan prakarya) melalui pendekatan tematik. Bidang seni tari merupakan salah satu media berkomunikasi (berekspresi seni) yang memiliki daya tarik bagi anak SD. Berkreasi seni tari dapat mengembangkan kompetensi dasar motorik halus yang sesuai dengan masa-masa perkembangan yang bersifat polos, unik, kreatif, spontanitas, dan dinamis. Pemberian pengalaman belajar pada masa peka ini merupakan saat yang paling baik, karena dapat mengembangkan kemampuan anak baik fisik dan psikis secara utuh dan bermakna. Pembelajaran seni tari di sekolah dasar kaitannya dengan Kurikulum 2013 (K-13) orientasi materi terkait pada karakteristik siswa, mengarah pada aspek budaya lokal dan nilai-nilai ke-Nusantara-annya. Untuk itu pengembangan desain pembela-jaran seni tari sesuai dengan kebutuhan pembela-jaran siswa sekolah dasar dengan pemanfaatan pengetahuan keunggulan-keunggulan budaya daerah (localgenius knowledge) Bali melalui pembelajaran terpadu (integrated learning) penting dilakukan, sehingga memberi beragam pengalaman belajar bagi anak untuk tercapainya tujuan pembelajaran seni lebih bermakna. 


\section{UCAPAN TERIMAKASIH}

Kami mengucapkan terima kasih yang sebanyakbanyaknya kepada pemerintah Republik Indonesia cq Direktur Riset dan Pengabdian Masyarakat Ditjen Penguatan Riset dan Pengembangan Kemenristekdikti yang memberikan kesempatan dan bantuan finansial sehingga dapat mengikuti progam penelitian hibah bersaing ini.

Pada kesempatan ini penulis menyampai-kan ucapan terima kasih kepada Bapak Rektor Institut Seni Indonesia Denpasar, Ketua Lembaga Penelitian dan Pengabdian Kepada Masyarakat Institut Seni Indonesia Denpasar, Dekan Fakultas Seni Pertunjukan Institut Seni Indonesia Denpasar beserta jajarannya. Dalam pelaksanaan penelitian ini sangat banyak mendapat bantuan dari para nara sumber dan semua pihak yang membantu secara langsung maupun tidak langsung yang namanya tidak dicantumkan pada tulisan ini diucapkan terima kasih.

Tentunya ada hal-hal yang ingin kami berikan kepada masyarakat dari hasil karya ilmiah ini. Karena itu kami berharap semoga karya ilmiah ini dapat menjadi sesuatu yang berguna bagi kita bersama. Kiranya Ida Hyang Widhi Wasa/Tuhan Yang Maha Esa akan memberikan perlindungan dan anugrah yang berlimpah-limpah.

\section{DAFTAR RUJUKAN}

Agung, AA Gde Putra. 1981. Magebug dan Mekare Seni Tari Tradisional di Karangasem. Proyek Media Kebudayaan Jakarta Direktorat Jendral Kebudayaan Departemen Pendidikan dan Kebudayaan.

Ayatrohaedi. 1986. Kepribadian Budaya Bangsa (Localgenius). Jakarta : Pustaka Jaya.

Cote, Paulette. 2006. The Power of Dance in Society and Education: Lessons Learned from Tradition and Innovation, Provide a Solid Founda-tion for Dance Education. The Journal of Physical Education, Recreation \& Dance, Vol. 77.

Damayanti, Deni. 2014. Panduan Implementasi Pendidikan Karakter Di Sekolah. Araska: Yogyakarta.
Dantes, N. 2014. Landasan Pendidikan, Tinjauan dari Dimensi Makropedagogis. Kementerian Pendidikan dan Kebudayaan Universitas Pendidikan Ganesha Program Pascasarjana: Singaraja

Depdiknas. 2006. Panduan Pengembangan Silabus Mata Pelajaran Seni Budaya Sekolah Menegah Pertama. Direktoral Jenderal Pendidi-kan Dasar dan Menengah. Direktorat Pendidikan Sekolah Mengenah Pertama. Jakarta.

Djelantik, A.A.M. 2004. Estetika Sebuah Pengantar. Bandung: Masyarakat Seni Pertunju-kan Indonesia (MSPI).

Dewantara, Ki Hajar. 1977. Bagian Pertama Pendidikan. Majelis Luhur Persatuan Taman-siswa: Yogyakarta.

Elindra, Yetti. 2011. Tari Pendidikan Sebagai Upaya Pembentukan Karakter Anak Usia Dini Melalui Penerapan Model Pembelajaran Terpadu. Proceeding. Seminar Nasional "Seni Berbasis Pluralitas Budaya Menuju Pendidikan Karakter "Pembelajaran Tari Pendidikan Sebagai Upaya Pembentukan Karakter Anak Usia Dini Melalui Model Pembelajaran Terpadu" ISBN: 979-261879-1, Hal. 18-28, 11-12 November 2011: Yogyakarta.

Eiseman Jr, Fred B. 1990. Bali: Sekala \& Niskala. Singapore: Periplus.

Fuad Hassan, 1989. Renungan Budaya. Balai Pustaka: Jakarta.

Gagnon dan Collay. 2001. Pengertian Komponen dan Desain. Diakses tanggal 2 Maret 2015).

Gede Agung, AA. 1996/1997. Nilai-nilai Budaya Daerah yang Terkait dengan Nilai-nilai Luhur Pancasila. Denpasar

Geriya, I Wayan. 2000. Transformasi Kebudaya-an Bali Memasuki Abad XXI. Denpasar: Dinas Kebudayaan Propinsi Bali.

http://sarinur.blogspot.com/2011/02/saya-banggamenjadi-bangsa-indonesia.html (Diakses 28 Februari 2016) 
Ni Luh Sustiawati, Ni Ketut Suryatini, Anak Agung Ayu Mayun Artati (Pengembangan Desain Pembelajaran...)

http://www.akamigas.ac.id/stem/index.php/bangga -sebagai-bangsa-indonesia.htm (Diakses 28 Februari 2016)

Komalasari, Heni. 2007. Aplikasi Model Pembelajaran Tari Pendidikan Di SDN Nilem 2 Ban-dung. Laporan Hasil Penelitian. Bandung: FPBS Universitas Pendidikan Indonesia:

Kusumohamidjojo, Budiono. 2000. Kebhinnekaan Masyarakat Indonesia: Suatu Problimatik Filsafat Kebudayaan. Jakarta: PT Gramedia Widiasarana Indonesia.

Leliweri, A. 2005. Prasangka dan Etnik Komunikasi Lintas Budaya Masyarakat Multikultur. Yogyakarta: LKiS.

Lemhanas. 1981. Kewiraan untuk Mahasiswa. PT Gramedia: Jakarta.

Miarso Yusufhadi, 2004. Menyemai Benih Teknologi Pendidikan. Jakarta. Pusat Teknologi Komunikasi dan Informasi Pendidikan Pustekkom Diknas.

Mudji Sutrisno, 2009: 110 dalam Artikel Mudra, https://core.ac.uk/download/pdf/12238593.pdf.

Muhammad, Abdulkadir. 2005. Ilmu Sosial Budaya Dasar. PT. Citra Aditya Bakti.

Munggah. I Made. 2008. Med-Medan Tradisi Unik Dari Sesetan. Denpasar: Pustaka Bali Post

Pamadhi. Hadjar. dkk. 2009. Pendidikan Seni di $S D$. Jakarta. Universitas Terbuka.

Purna, I Made. 2001. Fungsi Kearifan Lokal Dalam Upacara Peserta Ponan Pada Kehidupan Masyarakat Desa Poto. Tesis, tidak diterbitkan. Denpasar.

Rachmi. Tetty.dkk. 2015. Keterampilan Musik dan Tari. Tangerang Selatan. Universitas Terbuka

Ruhimat, Toto dkk. 2011. Kurikulum dan Pembelajaran. Jakarta: Rajagrafindo Persada.

Ruslan, Rosady. 2001. Etika Kehumasan. Jakarta: PT Raja Grafindo Persada.
MUDRA Jurnal Seni Budaya

Sartini. 2006. Menggali Kearifan Lokal Nusantara Sebuah Kajian Filsafati. http://filsafat.ugm.ac.id, diakses tanggal 20 Maret 2015.

Sedyawati, Edi. 2000. "Agama dan Kesenian: Permasalahan Data dan Interpretasinya". (Tulisan ini disampaikan pada pameran "Temuan Satu Abad (1900-1999): Perjalanan Sejarah.

Simpen, I W. 2003. Riwayat Kerajaan Buleleng (Buku Sejarah Ki Barak Panji Sakti). Surabaya: SIC.

Soehardjo, 2005. Pendidikan Seni dari Konsep sampai Program. Buku Satu, Malang: Balai Kajian Seni dan Desaín Jurusan Pendidikan Seni dan Desain Fakultas Sastra Universitas Negeri Malang.

Soekanto, Soeryono. 2003. Sosiologi (Suatu Pengantar). Jakarta: PT. Raja Grafindo Persada.

Suarka, Nyoman, dkk. 2011. Nilai Karakter Bangsa Dalam Permainan Tradisional Anak-Anak Bali. Denpasar: Udayana University Pers Kampus Universitas Udayana Denpasar.

Suhardana, K.M. 2006. Pengantar Etika dan Moralitas Hindu: Bahan Kajian Untuk Memperbaiki Tingkah Laku. Surabaya: Paramita.

Sumardjo, Jakob. 2000. Filsafat Seni. Bandung: ITB.

Suseno, Frans Magniz. 1993. Etika Jawa, Sebuah Analisis Falsafah Tentang Kebijaksanaan Hidup Jawa. Jakarta: Gramedia Pustaka Utama.

Sustiawati, 2008. Pengembangan Manajemen Pelatihan Seni Tari Multikultur Berpendekatan Silang Gaya Tari Bagi Guru Seni Tari Sekolah Menengah Pertama Negeri Di Kota Denpasar. Disertasi tidak diterbitkan. Malang: Program Pascasarjana UM.

Sutaba, dkk. 2002. Manfaat Arkeologi Untuk Memperkokoh Integrasi Bangsa. Denpasar: Upada Sastra.

The Liang Gie. 1976. Garis Besar estetika (Filsafat Keindahan). Yogyakarta: Karya Kencana 
Undang-Undang No. 20 tahun 2003 Tentang Sistem Pendidikan nasional (Sisdiknas)

Wadjiz Anwar, L.Th., 1980. Filsafat Estetika. Yogyakarta: Nur Cahaya.
Wiana, Ketut, 2002. Makna Upacara Dalam Agama Hindu. Surabaya: Paramita.

Windia, Nyoman, 2006. Konsep Tri Hita Karana Dalam Tradisi Bali. Surabaya: Paramita.

www.cakrawayu.org/.../48-seni-tradisi-indonesiasebagai-komponen bela negara 